\title{
Two different troponin isoforms for detecting early myocardial injury after curative resection of oesophageal cancer
}

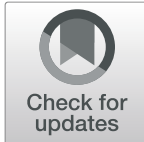

Wei Gu, Wei Tang, Zuojing Zhang, Meiying Xu and Jingxiang Wu* (1)

\begin{abstract}
Background: The objective of this study was to explore the consistency and correlation of two troponin (cTn) subtypes, troponin I (cTnl) and high-sensitivity troponin T (hs-cTnT), which can be used to judge early myocardial injury after curative resection of oesophageal cancer.

Methods: This study is a secondary analysis of data obtained from a previous randomized controlled trial on postoperative myocardial injury in 70 patients undergoing elective curative resection of oesophageal cancer who were randomly assigned to undergo aggressive body temperature management (nasopharyngeal temperature $\left.36.61 \pm 0.18^{\circ} \mathrm{C}\right)$ or standard body temperature management $\left(35.80 \pm 0.18^{\circ} \mathrm{C}, n=35\right.$ in each arm). The serum $\mathrm{cTnl}$ and hs-cTnT levels were measured in each patient at the 4 time points: before the operation and $6 \mathrm{~h} \sim 12 \mathrm{~h}, 24 \mathrm{~h}$ and $48 \mathrm{~h}$ after the operation. The diagnostic criteria of myocardial injury followed the third edition ESC/ACCF definition of myocardial infarction. The primary outcomes included the following: (1) the incidence of myocardial injury and the relationship between hs-cTnT and cTn and (2) the consistency and correlation of the two cTn subtypes.
\end{abstract}

Results: A total of 280 pairs of cTn samples were tested. The incidence of postoperative day 2 myocardial injury was 8.6\% (3/35) among patients receiving aggressive body temperature management and 31.4\% (11/35) among patients receiving standard body temperature management $(P<0.05)$. Among 3 patients who experienced myocardial injury in the aggressive body temperature management group, 2 met the diagnostic criteria for cTnl and hs-cTnT and only 1 met the diagnostic criteria for hs-cTnT. Among the 11 patients who experienced myocardial injury in the standard body temperature management group, 7 met the diagnostic criteria for cTnl and hs-cTnT and only 3 met the diagnostic criteria for hs-cTnT; only 1 met the diagnostic criteria for cTnl. The bias of cTnl and hs-cTnT was $-8.82 \pm 31.91 \mathrm{ng} / \mathrm{L}$. The consistency limit was $-71.37 \sim 53.73 \mathrm{ng} / \mathrm{L}$. The proportion within the scope of the consistency of its corresponding boundary was $98.57 \%$. The correlation coefficient of cTnl and hs-cTnT was $0.845(P<0.05)$.

Conclusions: In the evaluation of postoperative myocardial injury in patients undergoing curative resection of oesophageal cancer, cTnl and hs-cTnT exhibit high consistency and a good correlation. The combination of cTnl and hs-cTnT can improve the detection rate of myocardial injury, thus providing a better reference than a single measure alone for reducing the risk of perioperative myocardial injury in patients.

(Continued on next page)

\footnotetext{
* Correspondence: Wu_jingxiang@shchest.org

Department of Anaesthesiology, Shanghai Chest Hospital, Shanghai Jiao

Tong University, No. 241 Huaihai Rd. West, Shanghai, China
}

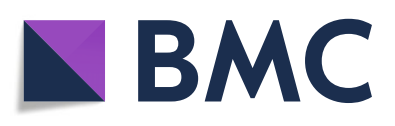

(c) The Author(s). 2020 Open Access This article is licensed under a Creative Commons Attribution 4.0 International License, which permits use, sharing, adaptation, distribution and reproduction in any medium or format, as long as you give appropriate credit to the original author(s) and the source, provide a link to the Creative Commons licence, and indicate if changes were made. The images or other third party material in this article are included in the article's Creative Commons licence, unless indicated otherwise in a credit line to the material. If material is not included in the article's Creative Commons licence and your intended use is not permitted by statutory regulation or exceeds the permitted use, you will need to obtain permission directly from the copyright holder. To view a copy of this licence, visit http://creativecommons.org/licenses/by/4.0/ The Creative Commons Public Domain Dedication waiver (http://creativecommons.org/publicdomain/zero/1.0/) applies to the data made available in this article, unless otherwise stated in a credit line to the data. 
(Continued from previous page)

Trial registration: ChiCTR-INR-17011621. Registered June 10, 2017.

Keywords: Anaesthesia, Postoperative myocardial, Oesophageal Cancer, Troponin

\section{Background}

The incidence of myocardial injury after major noncardiac surgery is approximately $8 \%$, and myocardial injury is one of the major risk factors for perioperative adverse events [1]. Currently, high-sensitivity troponin $\mathrm{T}$ (hs-cTnT) and cTnI are commonly used in clinical practice to diagnose myocardial injury and predict cardiac complications after non-cardiac surgery. However, the better option between cTnI and cTnT remains a question of debate. This study is a secondary analysis of data obtained from a previous randomized controlled trial on postoperative myocardial injury in middle-aged and elderly patients following curative resection of oesophageal cancer with aggressive or standard body temperature management (registered at http://www.chictr.org.cn/ showproj.aspx? Proj $=18,675$; the results have been published in the journal Anesthesia \& Analgesia [2]). In this study, hs-cTnT and cTnI were compared to reflect the changes in the myocardial injury detection rate. Curative resection of oesophageal cancer as a major non-cardiac operation is characterized by a wide range of operations, a long operation time, and large trauma. We found that patients undergoing curative resection of oesophageal cancer are prone to perioperative hypothermia and are at a relatively high risk of postoperative myocardial injury. Myocardial injury most often occurs within postoperative day 2. Among the patients who experience myocardial injury, $16 \%$ exhibit symptoms of myocardial ischaemia and $84 \%$ exhibit no symptoms of myocardial ischaemia and no significant electrocardiogram changes; therefore, myocardial injury can be diagnosed only by elevated troponin (cTn) [3]. The European Society of Cardiology (ESC)/American College of Cardiology Foundation (ACCF)/American Heart Association (AHA)/ World Heart Federation (WHF) jointly issued the third edition definition of myocardial infarction. According to the definition, slight myocardial injury can be detected by cTn in the early postoperative period [4]. cTn exists only in cardiomyocytes and is a complex composed of troponin $\mathrm{T}(\mathrm{cTnT})$, troponin $\mathrm{I}(\mathrm{cTnI})$ and troponin $\mathrm{C}$ (cTnC) [5]. hs-cTnT is a unique regulatory protein located on cardiac fibres. The minimum concentration of the fifth-generation hs-ctnt STAT assay is $3 \mathrm{pg} / \mathrm{ml}$, and its positive predictive value is approximately $95 \%$. cTnI is a unique contractility protein, its normal values range from 0 to $0.03 \mathrm{~g} / \mathrm{L}, \mathrm{cTnI} \geq 0.04 \mathrm{~g} / \mathrm{L}$ can be diagnosed as myocardial infarction [6], and the positive predictive value of the third-generation enhanced AccuTnI assay is approximately $60 \%$. Although hs-cTnT and cTnI are both sensitive indicators for the detection of myocardial injury, hs-cTnT and cTnI have the risk of missing early myocardial injury. The purpose of this study was to explore the value of hs-cTnT and cTnI in the determination of early myocardial injury after curative resection of oesophageal cancer to improve the detection rate of early postoperative myocardial injury and reduce the risk of perioperative myocardial injury in patients.

\section{Methods \\ Patients}

This study is a secondary analysis of data obtained from a previous randomized controlled trial on postoperative myocardial injury in middle-aged and elderly patients following curative resection of oesophageal cancer with aggressive or standard body temperature management [2]. This study protocol was approved by the Ethics Committee of Shanghai Chest Hospital (Institutional Review Board\# KS1614), and written informed consent was obtained from all subjects participating in the trial before enrolment. The trial was registered before patient enrolment at chictr.org.cn (ChiCTR-INR-17011621, principal investigator: Jingxiang $\mathrm{Wu}$, date of registration: June 10, 2017).

Seventy-five patients scheduled for elective oesophageal cancer surgery were assessed for eligibility. All patients underwent thoracoscopic triple incision oesophageal carcinoma surgery (McKeown surgery). Patients underwent an open oesophagectomy in the left lateral decubitus position and were then switched to the supine position with the head tilted to the right to complete the abdominal and neck surgery. The inclusion criteria were as follows: (1) patients classified as having an ASA physical status of I or II and who had been scheduled to receive curative resection of oesophageal carcinoma under general anaesthesia, (2) age 45-80 years, and (3) expected surgery duration of $2-6 \mathrm{~h}$. The exclusion criteria were as follows: (1) major cardiovascular diseases at baseline; (2) preoperative serum cTnI > $0.03 \mathrm{ng} / \mathrm{mL}$; (3) body mass index $>30 \mathrm{~kg} / \mathrm{m}^{2}$; (4) endstage renal disease requiring dialysis; (5) major infection, including but not limited to septicaemia; or (6) clinically important coagulopathy. 


\section{Measurements}

Based on a computer-generated randomization sequence, patients were randomly assigned to receive either aggressive or standard body temperature management. Patients were randomly assigned to each group at a 1:1 ratio. An opaque, sealed envelope was opened to determine the patient's group assignment after the patient had provided written informed consent. Patients were not informed of their treatment assignment. In the standard body temperature management arm, the heating pad was off on patient arrival and turned on only if the body temperature dropped to $35.0^{\circ} \mathrm{C}$. An additional heating pad was applied to the neck and shoulder areas if the body temperature remained at $<35.0^{\circ} \mathrm{C}$ for $20 \mathrm{~min}$. The heating pad was turned off if the body temperature reached $35.2^{\circ} \mathrm{C}$. In the aggressive management arm, the heating pad was turned on upon patient arrival and turned off if body temperature increased to $37.0^{\circ} \mathrm{C}$. It was turned on if the body temperature decreased to $36.5^{\circ} \mathrm{C}$. An additional heating pad was applied to the neck and shoulder areas if the body temperature dropped to $36.0^{\circ} \mathrm{C}$. The same surgeons operated on both groups and were not blinded to allocation.

Blood was drawn before surgery and at 6-12, 24, and $48 \mathrm{~h}$ after surgery. A secondary analysis was performed on the abovementioned frozen blood samples for the measurement of serum hs-cTnT and cTnI. cTnI levels were assayed using a third-generation enhanced AccuTnI assay (Beckman Coulter, Brea, CA), while hscTnT levels were assayed using a fifth-generation hscTnT STAT assay (Roche Diagnostics, Shanghai, China). The laboratory technicians performing these assays were blinded to patient allocation.

Myocardial injury was defined as cTnI $>0.06 \mu \mathrm{g} / \mathrm{L}$ during the first 2 postoperative days; this was the lowest measurable value, with a $10 \%$ coefficient of variation above the 99th percentile of $0.04 \mu \mathrm{g} / \mathrm{L}$ for the assay used [7]. Alternatively, myocardial injury was defined as the occurrence of hs-cTnT $\geq 0.065 \mu \mathrm{g} / \mathrm{L}$ or $0.02 \mu \mathrm{g} / \mathrm{L} \leq \mathrm{hs}-$ $\mathrm{c} \operatorname{TnT}<0.065 \mu \mathrm{g} / \mathrm{L}$ but with an absolute change of at least $0.005 \mu \mathrm{g} / \mathrm{L}$. [1, 4] Myocardial injury was defined as elevated cTnI or hs-cTnT because the 2 measures carry distinct sensitivity and specificity and are both implicated in myocardial injury. Additionally, the timing of the 2 measures was different.

\section{Statistical analysis}

SPSS 22.0 (IBM, Chicago, IL) was used for data analysis. Data were tested for normal distribution, and data showing a normal distribution are expressed as the mean \pm standard deviation (SD). Data showing a skewed distribution are expressed as the median (interquartile range). Chi-square tests were used for categorical variables based on the two cTn concentrations. The incidence of myocardial injury was calculated. A Venn diagram was drawn for the diagnosis of myocardial injury with hscTnT and cTnI elevation. The consistency between the two cTn concentrations was analysed by the BlandAltman method. Bias is defined as the mean of the difference between two cTn concentrations and represents systematic error, whereas SD of bias represents random error or variability; the consistency limit is bias $\pm 2 \mathrm{SD}$. The percentage of the difference between the two cTn concentrations within the consistency threshold indicates the percentage within the consistency limit. Pearson's correlation analysis was performed to compare the two cTn concentrations. $P$-values $<0.05$ were considered statistically significant.

\section{Results}

\section{Baseline characteristics}

We initially assessed 75 patients for eligibility, of whom 70 were enrolled, and all completed follow-up (Fig. 1). A total of 280 test data sets were collected, including 210 test data sets $48 \mathrm{~h}$ after surgery. According to 210 test data sets $48 \mathrm{~h}$ after surgery, 3 patients in the aggressive body temperature management group experienced myocardial injury, and 11 patients in the standard body temperature management group experienced myocardial injury. $\mathrm{T}$ tests were performed in both groups. According to the incidence of myocardial injury, a Venn diagram and a scatter diagram of the relationship between cTnI and hs-cTnT were drawn. A total of 140 data pairs were included in the Bland-Altman consistency analysis and Pearson's correlation analysis.

\section{Diagnostic efficacy for myocardial injury}

The incidence of myocardial injury during the first 2 postoperative days was $8.6 \%(3 / 35)$ in the aggressive body temperature management group and $31.4 \%$ (11/35) in the standard body temperature management group $(P<0.05$, Fig. 2a). Among patients who experienced myocardial injury, both the cTnI and hs-cTnT criteria for myocardial injury were met in 3 patients in the aggressive body temperature management group and 11 patients in the standard body temperature management group. Based only on the cTnI criterion, myocardial injury occurred in 2 patients in the aggressive body temperature management group and 8 patients in the standard body temperature management group. Based only on the hs-cTnT criterion, myocardial injury occurred in 3 patients in the aggressive body temperature management group and 10 patients in the standard body temperature management group (Fig. 2b).

The number of myocardial injury samples and the concentration of cTn in the aggressive body temperature management group were significantly lower than those 


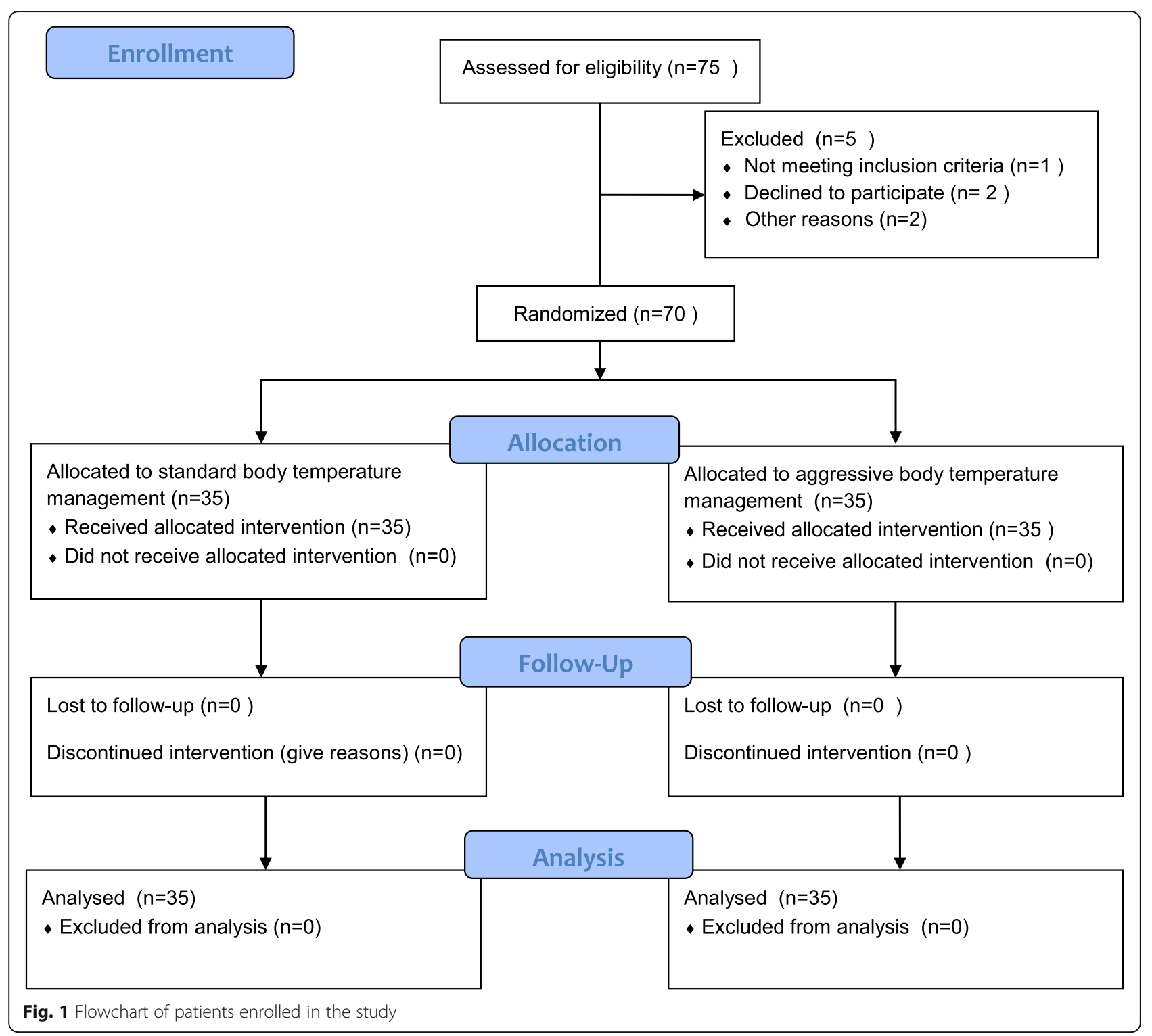

in the standard body temperature management group at postoperative $6 \mathrm{~h} \sim 12 \mathrm{~h}, 24 \mathrm{~h}$ and $48 \mathrm{~h}$ (Fig. 2c). Based only on the cTnI criterion, the area shown in (1) would be missed. Based only on the hs-cTnT criterion, the area shown in (2) would be missed. However, based on both the cTnI and hs-cTnT criteria, more myocardial injuries would be found to avoid a missed diagnosis and for the timely treatment of patients. Therefore, myocardial injury can more easily be detected, the number of missed diagnoses can be reduced, and patients can be treated in a timely manner.

\section{Bland-Altman consistency analysis}

The scatter diagram of the difference between hs-cTnT and cTnI plotted against the average of the two shows that the bias is $-8.82 \pm 31.91 \mathrm{ng} / \mathrm{L}$ and that the consistency limits are - 71.37-53.73 ng / L, indicating that the consistency between hs-cTnT and cTnI is good; the percentage within the consistency limit is $98.57 \%$ (Table 1) (Fig. 3).

\section{Pearson's correlation analysis}

The correlation analysis (Pearson: r) between cTnt and cTnl is shown in Fig. 4. Good positive correlation was observed. The correlation coefficient ( $r$ ) between hscTnT and cTnI was $0.845(P<0.01$, Fig. 4$)$.

\section{Discussion}

The incidence of perioperative hypothermia, which is likely to cause perioperative myocardial injury, is high during curative resection of oesophageal cancer under general anaesthesia [3]. When myocardial injury occurs, cTn and creatine kinase isoenzyme (ck-mb) in the blood 


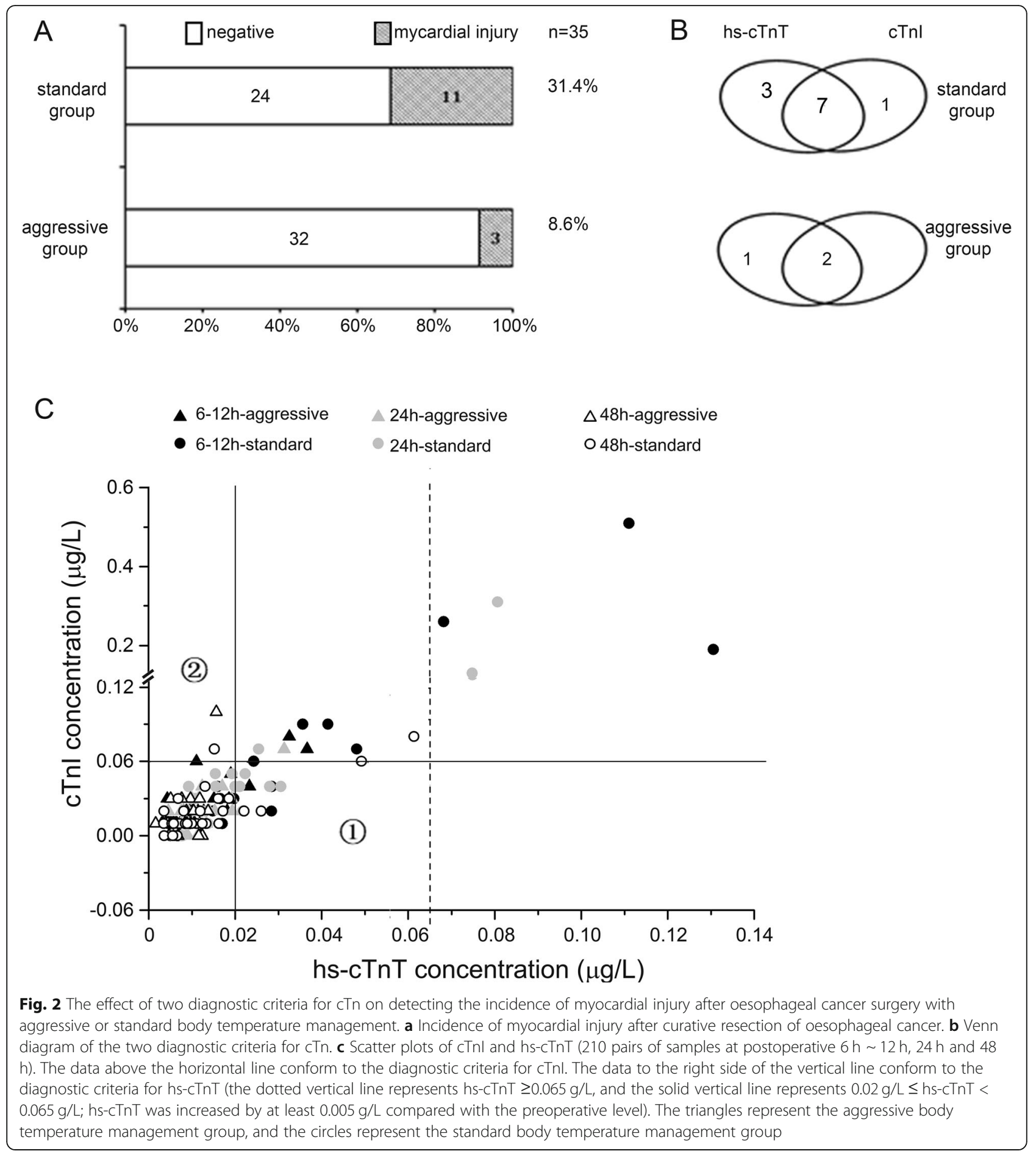

Table 1 Comparison of bias, standard deviation and consistency limits between hs-cTnT and cTnl

\begin{tabular}{|c|c|c|c|c|c|c|c|}
\hline \multirow[t]{2}{*}{ Index } & \multirow[t]{2}{*}{$\begin{array}{l}\text { hs-cTnT } \\
\text { (ng/L, } \bar{x} \pm S D)\end{array}$} & \multirow{2}{*}{$\begin{array}{l}\text { cTnl } \\
\left(\mathrm{ng} / \mathrm{L}_{\bar{x}} \pm \mathrm{SD}\right)\end{array}$} & \multirow[t]{2}{*}{$\begin{array}{l}\text { Bias } \\
\text { (ng/L) }\end{array}$} & \multirow{2}{*}{$\begin{array}{l}\text { Standard } \\
\text { deviation of } \\
\text { bias (ng/L) }\end{array}$} & \multicolumn{2}{|c|}{ Consistency limit } & \multirow[t]{2}{*}{$\begin{array}{l}\text { Percentage within the } \\
\text { consistency limit (\%) }\end{array}$} \\
\hline & & & & & low & high & \\
\hline Count & $11.39 \pm 13.83$ & $20.21 \pm 42.74$ & -8.82 & 31.91 & -71.37 & 53.73 & $98.57 \%$ \\
\hline
\end{tabular}




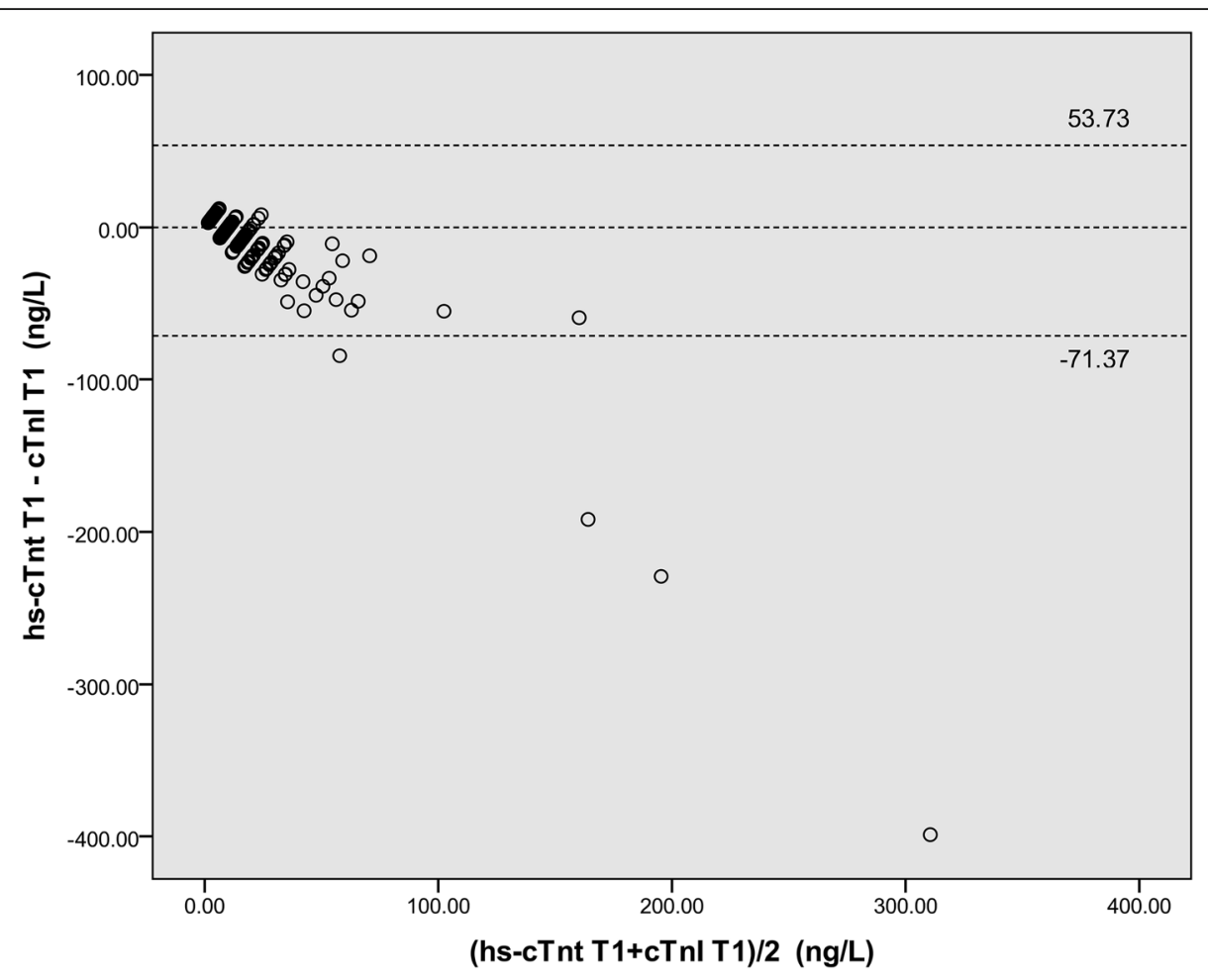

Fig. 3 Bland-Altman scatter diagram

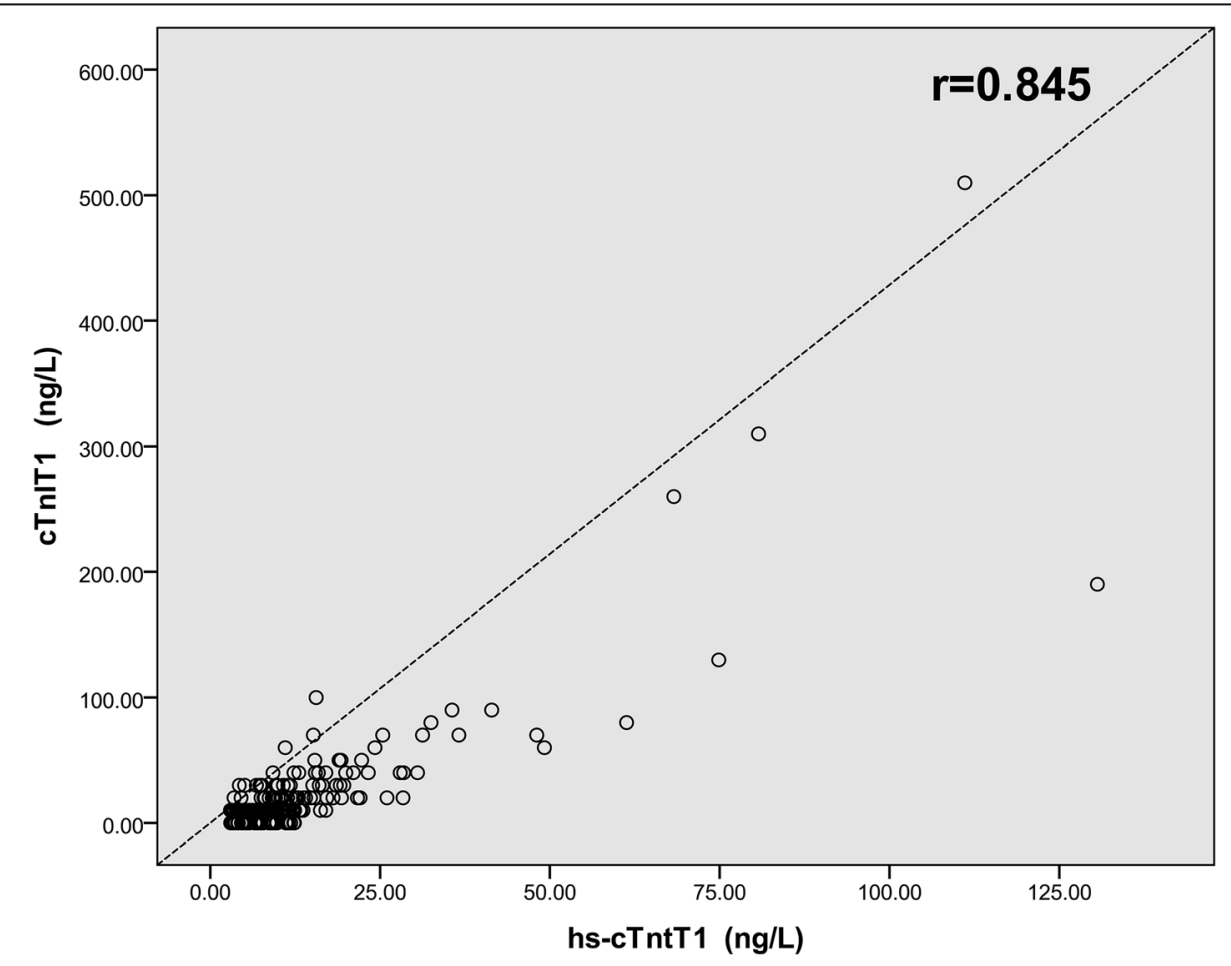

Fig. 4 Pearson's correlation analysis of hs-cTnT and cTnl 
increase. $\mathrm{cTn}$ has higher sensitivity and specificity than ck-mb, which is widely used in clinical practice [8]. cTn is a new marker for the diagnosis of myocardial injury. Clinically, cTn includes cTnI and cTnT, which have high sensitivity and specificity to myocardial injury. cTnI and cTnT are currently considered the best diagnostic markers and have become the "gold standard" for the diagnosis of myocardial injury [9-11]. Therefore, the postoperative monitoring of hs-cTnT and cTnI can effectively improve the detection rate of early postoperative myocardial injury, which is particularly important in the prevention of perioperative myocardial injury.

hs-cTnT is a specific regulatory protein, and cTnI is a specific contractile protein on myocardial fibres. When the myocardial cell membrane is intact, neither hs-cTnT nor cTnI can penetrate the cell membrane into the peripheral blood circulation, so hs-cTnT and cTnI cannot be detected in the peripheral blood of healthy people [5]. cTnI, a non-enzymatic serum marker with high specificity and sensitivity, is one of the most commonly used markers for detecting myocardial injury. When the myocardium is damaged, cTnI is released into the blood, which increases at $3-5 \mathrm{~h}$, peaks at $24 \mathrm{~h}$, and decreases to normal at 5-10 days. hs-cTnT is highly sensitive to myocardial injury, which can appear in the early stage of myocardial injury, and can even detect the release of free cTnI and trace cTnI in the cytoplasm. When cTnI cannot be detected, hs-cTnT can be detected at a very low concentration, improving the early diagnosis of myocardial infarction and saving the lives of patients with strong timely support [12-14]. Meanwhile, when hscTnT cannot be detected, cTnI might be an alternative. Therefore, they can be a complementary method to improve the detection rate of myocardial injury.

This study explored the value of hs-cTnT and cTnI in the determination of early myocardial injury after curative resection of oesophageal cancer. The results showed that if hs-cTnT and cTnI were simultaneously detected within the first 2 postoperative days, the incidence of myocardial injury was $8.6 \%$ (3/35) among patients receiving aggressive body temperature management and 31.4\% (11/35) among patients receiving standard body temperature management. If only cTnI was detected, the incidence of myocardial injury was $5.7 \%(2 / 35)$ among patients receiving aggressive body temperature management and 25.7\% (9/35) among patients receiving standard body temperature management. Similarly, if only hs-cTnT was detected, the incidence of myocardial injury was $8.6 \%$ (3/35) among patients receiving aggressive body temperature management and 28.6\% (10/ 35) among patients receiving standard body temperature management. Therefore, the combination of cTnI and hscTnT as the diagnostic standard of myocardial injury can be used to more easily detect myocardial injury to avoid missed diagnoses and to treat patients in a timely manner.
To clarify the correlation and reliability of cTnI and hs-cTnT, this study further analysed the consistency and correlation between cTnI and hs-cTnT. Bland-Altman consistency analysis showed that the percentage within the consistency limit of hs-cTnT and cTnI was $98.57 \%$, which was higher than the 95\% standard, indicating good consistency. The Pearson correlation coefficient of hs-cTnT and cTnI was above 0.8 , indicating a good correlation. Therefore, cTnI and hs-cTnT have complementary effects in the detection of myocardial injury.

Several limitations to this study exist. First, the subjects were only patients who received curative resection of oesophageal cancer, and no other patients were studied. Second, the sample size of this study was small; only 14 patients suffered myocardial injury within the first 2 postoperative days. Finally, there is currently a lack of long-term follow-up of these patients with myocardial injury. This will require further research.

\section{Conclusions}

In the evaluation of postoperative myocardial injury in patients undergoing curative resection of oesophageal cancer, cTnI and hs-cTnT exhibit high consistency and a good correlation. The combination of cTnI and hscTnT can improve the detection rate of myocardial injury, thus providing a better reference than a single measure alone for reducing the risk of perioperative myocardial injury in patients. Therefore, using both is a recommended method.

\section{Abbreviations}

cTn: troponin, troponin T (cTnT), troponin I (cTnl), and troponin C (cTnC); hsCTnT: high-sensitivity troponin T; ESC: European Society of Cardiology; ACCF: American College of Cardiology Foundation; AHA: American Heart Association; WHF: World Heart Federation

\section{Acknowledgements}

The authors thank Zhigang Li, MD, in the Department of Esophageal Surgery and Jiatao Lou, MD, in the Department of Laboratory Medicine at Shanghai Chest Hospital, Shanghai, China.

\section{Authors' contributions}

WG helped with the data collection and analysis and manuscript drafting. WT and ZZZ helped with patient enrolment and follow-up and data collection. MYX helped with the study design and critical revision of the manuscript. JXW conceived the study and helped with the study design, data analysis and interpretation, critical revision of the manuscript, and approval of the final manuscript.

\section{Funding}

This work was supported by the National Natural Science Foundation of China Project (81671078) and Shanghai Municipal Commission of Health and Family Planning Project (201840319).

\section{Availability of data and materials}

The datasets used and/or analysed during the current study are available from the corresponding author on reasonable request.

Ethics approval and consent to participate

Clinical trial registration number: ChiCTR-INR-17011621. Registry URL: http:// www.chictr.org.cn/showproj.aspx?proj=18675. 


\section{Consent for publication}

Not applicable.

\section{Competing interests}

The authors declare that they have no competing conflicts of interest.

Received: 8 March 2020 Accepted: 13 July 2020

Published online: 25 July 2020

\section{References}

1. Writing Committee for the VSI, Devereaux PJ, Biccard BM, et al. Association of Postoperative High-Sensitivity Troponin Levels with Myocardial Injury and 30-day mortality among patients undergoing noncardiac surgery. JAMA. 2017;317(16):1642-51. https://doi.org/10.1001/jama.2017.4360.

2. Zhang Z, Xu M, Wu D, Zhang X, Wu J. Postoperative myocardial injury in middle-aged and elderly patients following curative resection of esophageal Cancer with aggressive or standard body temperature management: a randomized controlled trial. Anesth Analg. 2019;129(2):352-9. https://doi. org/10.1213/ANE.0000000000004022.

3. Botto F, Alonso-Coello P, Chan MT, et al. Myocardial injury after noncardiac surgery: a large, international, prospective cohort study establishing diagnostic criteria, characteristics, predictors, and 30-day outcomes. Anesthesiology. 2014;120(3):564-78. https://doi.org/10.1097/ALN. 0000000000000113.

4. Thygesen K, Alpert JS, Jaffe AS, et al. Third universal definition of myocardial infarction. Circulation. 2012;126(16):2020-35. https://doi.org/10.1161/CIR. Ob013e31826e1058.

5. Cheng $Y$, Regnier M. Cardiac troponin structure-function and the influence of hypertrophic cardiomyopathy associated mutations on modulation of contractility. Arch Biochem Biophys. 2016;601:11-21. https://doi.org/10.1016/ j.abb.2016.02.004.

6. Lee GR, Jhanji S, Tarrant H, James S, Pearse RM, Fitzgibbon M. Peri-operative troponin monitoring using a prototype high-sensitivity cardiac troponin I (hs-cTnl) assay: comparisons with hs-cTnT and contemporary cTnl assays. Ann Clin Biochem. 2014;51(Pt 2):258-68. https://doi.org/10.1177/ 0004563213494078 .

7. van Waes JA, Nathoe HM, de Graaff JC, et al. Response to letter regarding article, "myocardial injury after noncardiac surgery and its association with short-term mortality". Circulation. 2014;129(5):e324. https://doi.org/10.1161/ CIRCULATIONAHA.113.007269.

8. Mastro F, Guida P, Scrascia G, et al. Cardiac troponin I and creatine kinaseMB release after different cardiac surgeries. J Cardiovasc Med. 2015;16(6): 456-64. https://doi.org/10.2459/JCM.00000000000000044.

9. Nestelberger T, Wildi K, Boeddinghaus J, et al. Characterization of the observe zone of the ESC 2015 high-sensitivity cardiac troponin 0h/1halgorithm for the early diagnosis of acute myocardial infarction. Int J Cardiol. 2016;207:238-45. https://doi.org/10.1016/j.jjcard.2016.01.112.

10. Jaeger $C$, Wildi $K$, Twerenbold $R$, et al. One-hour rule-in and rule-out of acute myocardial infarction using high-sensitivity cardiac troponin I. Am Heart J. 2016;171(1):92-102 e1-5. https://doi.org/10.1016/j.ahj.2015.07.022.

11. Boeddinghaus J, Reichlin T, Cullen L, et al. Two-hour algorithm for triage toward rule-out and rule-in of acute myocardial infarction by use of highsensitivity cardiac troponin I. Clin Chem. 2016;62(3):494-504. https://doi.org/ 10.1373/clinchem.2015.249508.

12. Nagele P, Brown F, Gage BF, et al. High-sensitivity cardiac troponin T in prediction and diagnosis of myocardial infarction and long-term mortality after noncardiac surgery. Am Heart J. 2013;166(2):325-32 e1. https://doi.org/ 10.1016/j.ahj.2013.04.018

13. Weber M, Luchner A, Seeberger M, et al. Incremental value of high-sensitive troponin $\mathrm{T}$ in addition to the revised cardiac index for peri-operative risk stratification in non-cardiac surgery. Eur Heart J. 2013;34(11):853-62. https:// doi.org/10.1093/eurheartj/ehs445.

14. Kavsak PA, Walsh $M$, Srinathan $S$, et al. High sensitivity troponin $T$ concentrations in patients undergoing noncardiac surgery: a prospective cohort study. Clin Biochem. 2011;44(12):1021-4. https://doi.org/10.1016/j. clinbiochem.2011.05.017.

\section{Publisher's Note}

Springer Nature remains neutral with regard to jurisdictional claims in published maps and institutional affiliations.

\section{Ready to submit your research? Choose BMC and benefit from:}

- fast, convenient online submission

- thorough peer review by experienced researchers in your field

- rapid publication on acceptance

- support for research data, including large and complex data types

- gold Open Access which fosters wider collaboration and increased citations

- maximum visibility for your research: over $100 \mathrm{M}$ website views per year

At $\mathrm{BMC}$, research is always in progress.

Learn more biomedcentral.com/submissions 